\title{
Sertoli leydig cell tumor with rare form of presentation
}

\section{Sasikala Ramraj, Akshya Prabha Venkatakrishnan*, Gayathri Mohan}

Department of Obstetrics \& Gynaecology, Sri Manakula Vinayagar Medical College and Hospital, Kalitheerthalkuppam, Pondicherry, Tamil Nadu, India

Received: 30 July 2015

Accepted: 17 August 2015

*Correspondence:

Dr. Akshya Prabha V,

E-mail: drakshyaprabha@gmail.com

Copyright: (C) the author(s), publisher and licensee Medip Academy. This is an open-access article distributed under the terms of the Creative Commons Attribution Non-Commercial License, which permits unrestricted non-commercial use, distribution, and reproduction in any medium, provided the original work is properly cited.

\begin{abstract}
Ovarian sex cord stromal cell tumors occur most frequently in the third and fourth decades of life. $75 \%$ of these tumors are seen in women younger than 40 yrs. These neoplasms are extremely rare and account for $<0.5 \%$ of ovarian cancers. We present a case of 30 yr. old multiparous lady, with abdominal distension and pain, diagnosed with bilateral solid ovarian tumor and underwent staging laparotomy followed by total abdominal hysterectomy with bilateral salpingo oophorectomy and infracolic omentectomy. HPE revealed sertoli leydig cell tumor of intermediate differentiation on both sides. We present this case here for its rare presentation.
\end{abstract}

Keywords: Sex cord stromal tumors, Sertoli leydig cell tumor, Intermediate differentiation

\section{INTRODUCTION}

Ovarian sex cord-stromal tumors are rare kinds of neoplasm of the upper female genital tract. Sertoli-Leydig cell tumor of ovary belongs to sex cord-stromal tumors of ovary and accounts for less than $0.5 \%$ of all primary ovarian neoplasms. ${ }^{1}$ It is suggested to be arising either from gonadal mesenchyme of ovary or from remnants of hilum. ${ }^{2}$

\section{CASE REPORT}

Mrs. Rukkumani, 30 year old multiparous lady, presented to us with abdominal pain for 2 days and abdominal distension for 4 months, with a diagnosis of fibroid uterus or ovarian mass, referred to our institution for further evaluation.

She had associated loss of weight, loss of appetite, menorrhagia for $10 \mathrm{yrs}$. for which she did not undergo any treatment. On examination, she was poorly built and nourished. General condition was good. Vitals were stable. Examination revealed a pelvic mass up to the level of umbilicus, not felt separately from the uterus. She was subsequently evaluated with pre-operative investigations; CA 125 was 62.2, in favour of malignancy. Ultrasound showed a 19.5 x $11.1 \mathrm{cms}$ well defined, predominantly solid mass lesion noted arising from the right adnexa occupying pelvis and lower abdomen. The lesion showed few small $1 \mathrm{~cm}$ diameter areas within it. There were no calcifications, but was associated with increased internal vascularity. Low resistance arterial flow was noted. Similar lesion of $7.2 \times 3.27 \mathrm{cms}$ seen arising from the left adnexa. There was also moderate ascites and moderate right sided hydroureteronephrosis probably due to pressure effect on the right ureter by the mass. MRI Pelvis was done, reported as bilateral solid neoplastic ovarian lesions with associated moderate ascites, likely of sexcord stromal origin, more of fibrothecoma spectrum. Right ovarian lesion measuring $14.8 \times 10 \times 14 \mathrm{cms}$ and left ovarian lesion measuring 8.8 × 4.7 × $7 \mathrm{cms}$. Risk malignancy index was 186 , by which she comes into low risk category for malignancy (the cut off being 250). 
She underwent staging laparotomy followed by total abdominal hysterectomy with bilateral salpingo oophorectomy, infracolic omentectomy. Gross findings There was a right ovarian tumor measuring $15 \times 20 \mathrm{cms}$ and left ovarian tumor measuring $5 \times 6 \mathrm{cms} .30 \mathrm{ml}$ ascetic fluid was aspirated. Post-operative period was uneventful.

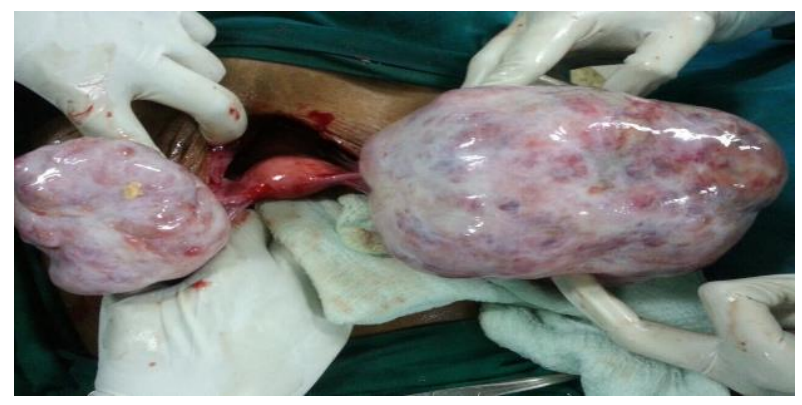

Figure 1: Intra-operative.

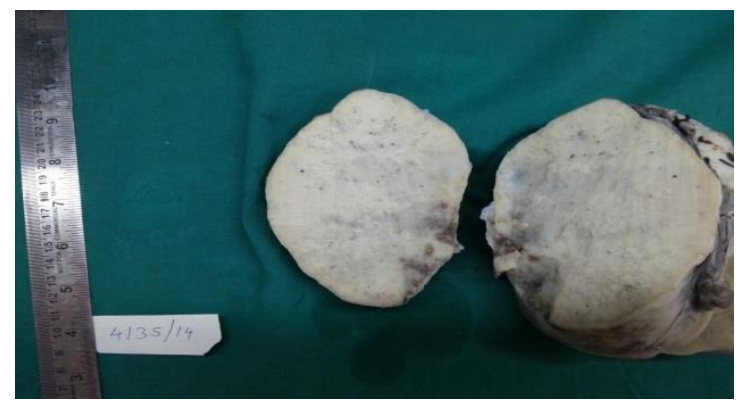

Figure 2: Cut section of the tumor.

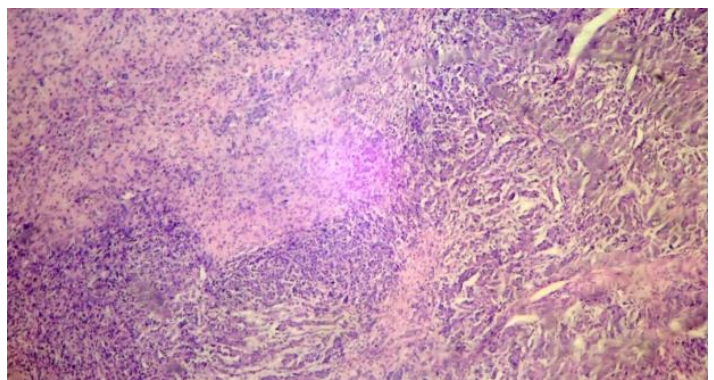

Figure 3: Tumor cells arranged in nests, cords, sheets.

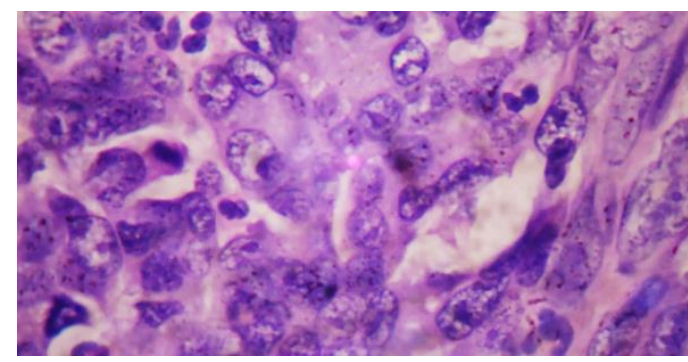

Figure 4: Coarse nuclear chromatin, hyperchromatic bizarre cells, mitotic activity.

Microscopic findings - Ascitic fluid showed few scattered lymphocytes, Uterus with cervix showed chronic cervicitis with squamous metaplasia, Left fallopian tube and ovary showed sertoli leydig cell tumor, intermediate differentiation, with lymphocytic invasion, Right fallopian tube and ovary - sertoli leydig cell tumor, intermediate differentiation, Omentum showed multiple sections showing tumor deposits into the omentum with secondary desmoplastic reaction and chronic inflammatory infiltrate.

By the above HPE report, FIGO surgical staging of this patient comes as STAGE 3B. Since she required postoperative chemotherapy; she was referred to higher centre.

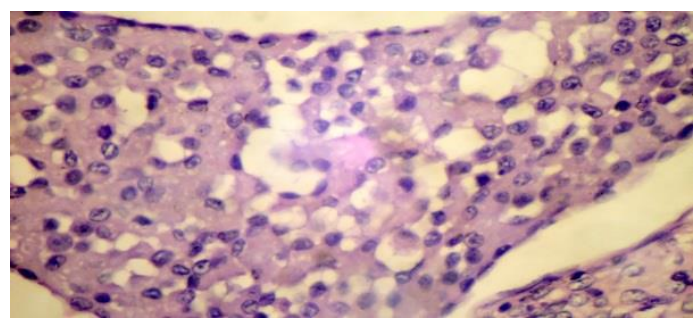

Figure 5: Leydig cell clusters in the stroma.

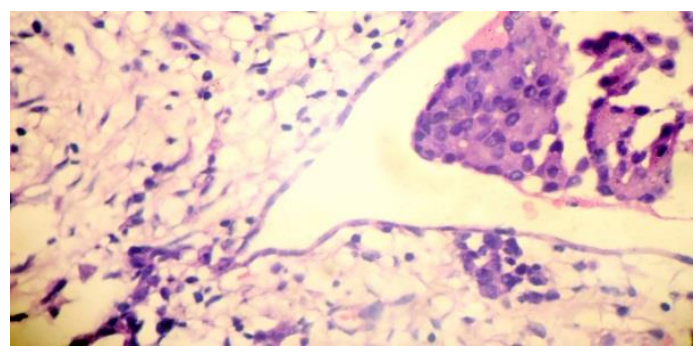

Figure 6: Tumor deposits in the omentum.

Immunohisto chemistry:

Cytokeratin - positive for the tumor cells

Vimentin - negative for tumor cells

\section{DISCUSSION}

Ovarian sex cord - stromal tumors are rare kinds of neoplasm of the upper female genital tract. Sertoli Leydig cell tumor of ovary belongs to sex cord-stromal tumors of ovary and accounts for less than $0.5 \%$ of all primary ovarian neoplasms. ${ }^{1}$

It is characterized by uncontrolled proliferation of naturally occurring testicular structures (Sertoli and Leydig cells) of varying degrees of differentiation which include well differentiated, moderately differentiated, poorly differentiated, and with heterologous elements. ${ }^{3}$ It is suggested to be arising either from gonadal mesenchyme of ovary or from remnants of hilum. Patients with SLCT present most commonly in second and third decades of life. These are usually unilateral but

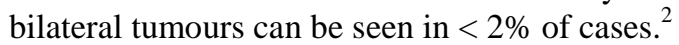

Clinical signs and symptoms of SLCT can be related to either hormonal production or presence of mass- 
occupying lesion. While SLCTs can be functionally inactive, abnormal hormonal production (mostly androgen or rarely estrogen excess) can be identified in more than half of patients). Clinical expression of virilization is recognized in more than one-third (33$38 \%$ ) of patients. Androgen-excess manifestations with varying degrees include virilism, hirsutism, hyperseborrhea, acne, receding hairline, alopecia, and hoarseness of voice, loss of subcutaneous tissue deposits, breast atrophy, clitoromegaly, oligomenorrhea and amenorrhea. Manifestations suggestive of excess estrogen include: precocious puberty, abnormal uterine bleeding, abnormal vaginal bleeding, menstrual irregularities, generalized edema, weight gain, breast hypertrophy, endometrial hyperplasia, endometrial polyps and endometrial carcinoma. ${ }^{3}$

Macroscopically, the majority of SLCTs range in size between 5 and $15 \mathrm{~cm}$ in diameter. In addition, SLCTs can be solid, solid and cystic or cystic. ${ }^{6}$ Average SLCT diameter is $13.5 \mathrm{~cm}$ and can reach as huge as $50 \mathrm{~cm}$ in poorly differentiated histological variants. ${ }^{1}$ However, as the size of SLCTs can sometimes be undetectable by ultrasonic, other imaging modalities such as computed tomography (CT), magnetic resonance imaging (MRI), and positron imaging tomography (PET) scans can be used for better recognization of SLCTs. ${ }^{1}$ The malignant potential of this tumor is lower than that observed for epithelial ovarian tumors, and the survival rate is $70 \%$ to $90 \%$ after a 5-year follow-up. ${ }^{11}$ Though the RMI calculation showed low risk for malignancy, the HPE report turned out to be malignancy in our case.

On USG, they have solid appearance, richly vascularization, lower vascular resistive index and peripheral necrosis. In general, malignant tumors have neovascularization and distension of pre-existing vessels, which result in a low resistance to blood flow. ${ }^{11}$ On the basis of endocrine symptoms, the woman's age and ultrasound findings; it should be possible to suggest a correct preoperative diagnosis of Sertoli cell, SertoliLeydig cell or Leydig cell tumors in many cases. ${ }^{10}$

Standard management guideline of ovarian SLCTs is still uncertain. Recommended treatment varies with patient age, tumor stage, and differentiation. Surgery is the initial method to deal with SLCTs. Fertility-sparing surgery (unilateral salpingooophorectomy) can be carried out in all well-differentiated ovarian SLCTs. Patients desiring fertility but exhibiting moderately or poorly differentiated ovarian SLCTs can be considered for unilateral salpingooophorectomy plus standard staging surgery (omentectomy, appendectomy, and pelvic lymphadenectomy). Patients who do not desire fertility or poorly-intermediately differentiated with intraoperative evidence of rupture and mesenchymal heterogonous elements containing subtypes should be considered for total hysterectomy, bilateral salpingooophorectomy in addition to complete standard staging surgery. ${ }^{1}$
Patients should be followed up with serum testosterone levels 3 months once for one year, 4 months once for one year, 6 months once for one year and then yearly once for rest of life. During follow-up, history, examination, serum testosterone and ultrasound abdomen and pelvis are done. If required, CT or MRI may be done. ${ }^{1}$ Age of the patient, stage of the disease and degree of tumor differentiation based on morphology are the most important factors considered in the management of the case. $^{8}$

As most Sertoli-Leydig cell tumors of the ovary are seen in young women and detected in early stages, favourable outcome can be achieved by conservative surgery. ${ }^{7}$ SLCTs have a good prognosis although we find recurrence of poorly differentiated tumors. The prognosis of patients with grade 1 SLCT is excellent without adjuvant chemotherapy. Patients with tumors of grade 2 or 3 appear to benefit from postoperative chemotherapy. ${ }^{5}$

\section{Funding: No funding sources \\ Conflict of interest: None declared \\ Ethical approval: Not required}

\section{REFERENCES}

1. Zhang HY, Zhu JE, Huang W, Zhu J., clinic pathologic features of ovarian sertoli-leydig cell tumors, International journal of clinical exp. Pathology. 2014;7(10):6956-64.

2. Kanade US, Dantkale SS, Narkhede RR, Kurawar RR, Bansode SY. Sertoli-Leydig cell tumor of ovary with menorrhagia: A rare case report. Journal of clinical and diagnostic research: JCDR. 2014;8(10); FD18-FD20.

3. Abu-Zaid A, Azzam A, Alghuneim LA, Metawee MT, Amin T, Al-Hussain TO. Poorly differentiated Ovarian Sertoli-leydig Cell Tumor in a 16-year-old single woman: A Case Report and Literature. Case Reports in Obstetrics and Gynecology. 2013:2013:858501.

4. Gui T, Cao D, Shen K, Zhang Y, Yu Q, Wan X et al. A clinicopathological analysis of 40 cases of ovarian sertoli leydig cell tumors, Journal of gynecological oncology. 2012;127(2):384-9.

5. Siqismondi C, Gadducci A, Lorusso D, Candiani M, Breda E, Raspagliesi F et al. Ovarian sertoli leydig cell tumors, a retrospective MITO study, Gynecologic oncology. 2012:125(3);673-6.

6. Chen L, Tunnell CD, De Petris G. Sertoli leydig cell tumor with heterologous element: a case report and a review of literature, International Journal of Clinical and Experimental Pathology. 2014;7(3):1176-81.

7. Bhat RA, Lim YK, Chia YN, Yam KL. Sertoli leydig cell tumor of ovary: ananlysis of a single institution database, The Journal of Obstetrics and Gynecology Research. 2013;39(1):305-10.

8. Sachdeva P, Arora R, Dubey C, Sukhija A, Daga M, Singh DK. Sertoli leydig cell tumor: a rare ovarian 
neoplasm. Case report and review of literature. Gynecological Endocrinology. 2008:24(4):230-4.

9. Movahedi Lankarani S, Kurman RJ. Calretinin: a more sensitive but less specific marker than alpha inhibin for ovarian sex cord stromal neoplasms: an immunohistochemical study of 215 cases, The American Journal of Surgical Pathology. 2002;26(11):1477-83.

10. Demidov VN, Lipatenkova J, Vikhareva O, Van Holsbeke C, Timmerman D, Valentin L. Imaging of gynecological disease: clinical and ultrasound characteristics of sertoli cell tumors, sertoli leydig cell tumor, leydig cell tumors, Ultrasound in Obstetrics and Gynecology. 2008;31(1):85-91.
11. Cleide Mara Mazzotti de Oliveira Franzin, Maria Lucia Kraft, Daniel Faundes, Luiz Carlos Zeferino, Marcelo Alvarenga, Emilo Francisco Marussi. Detection of ovarian sertoli leydig cell tumors exclusively by colour Doppler sonography, Journal of Ultrasound Med. 2006;25:1327-30.

12. Thrall MM, Paley P, Pizer E, Garcia R, Goff BA. Patterns of spread and recurrence of sex cord stromal tumors of the ovary, Gynecologic oncology. 2011,122(2):242-5.

Cite this article as: Ramraj S, Venkatakrishnan AP, Mohan G. Sertoli leydig cell tumor with rare form of presentation. Int J Reprod Contracept Obstet Gynecol 2015;4:1630-3. 